\title{
Effectiveness of zinc in modulating perinatal effects of arsenic on the teratological effects in mice offspring
}

\author{
Mohammad Ahmada, Mohammad A. M. Wadaan ${ }^{b}$, Muhammad Farooq ${ }^{b}$, Maha H. Daghestanic and Ahmed S. Sami ${ }^{\mathrm{d}}$ \\ a Department of Medical Surgical Nursing, College of Nursing. \\ b Department of Zoology, College of Science. \\ c Department of Zoology, Center for Scientific and Medical Female Colleges. \\ ${ }^{d}$ Department of Animal Production, College of Food and Agricultural Sciences; King Saud University, Riyadh, Saudi Arabia.
}

\begin{abstract}
Exposure to arsenic via drinking water is considered as a worldwide problem. Studies have shown that arsenic exposure during pregnancy affects embryogenesis and offspring development in rats and mice. Zinc as a micronutrient regulates many physiological functions, including an antioxidative role under various toxic conditions. However, studies on the perinatal protective effect of zinc on offspring need further attention. The present study was designed to evaluate the potential protective role of zinc in mitigating the adverse effects in the offspring of arsenic exposure during pregnancy. The arsenic (40 mg $/ \mathrm{kg}$ body weight) and zinc $(4 \% \mathrm{w} / \mathrm{v})$ doses formed the only drinking fluid source for the experimental groups of dams during the perinatal period of the experiment. The early development of sensory motor coordination reflexes together with morphological development in the male pups was measured during the weaning period. In adolescence, the offspring were tested for their motor behavior. The enzyme $\gamma$-glutamyl transferase $(\gamma-G T)$ and the oxidative stress indices like reduced glutathione (GSH) and lipid peroxidation (TBARS) were also estimated in the serum of the young adult male mice. Perinatal arsenic exposure caused depletion in body weight gain, delay in morphological development and retardation in the development of all sensory motor reflexes of the pups. In young adults, significant decrease in motor behavior with significant decrease in GSH level in the serum was observed. On the other hand, $\gamma$-GT and TBARS were significantly increased in the serum due to arsenic treatment. However, animals exposed to arsenic in the presence of zinc showed a remarkable ameliorating effect of zinc on all observed teratological and biochemical arsenic toxicity in male offspring. It was observed that zinc has an antioxidative role in the perinatal toxicity of arsenic. It is concluded from the present study that zinc consumed during the perinatal period of pregnancy can ameliorate the possible toxicities of arsenic exposure in the offspring by acting as an ameliorative supplement.
\end{abstract}

Key words: Arsenic, zinc, perinatal, mice offspring, sensory motor reflexes, behavior, oxidative stress.

\section{INTRODUCTION}

Chronic arsenic (AS) poisoning caused by exposure via drinking water has been reported in many countries of the world (Frisbie et al., 2002; Tian et al., 2001) and is considered as a widespread and worldwide problem (Jin et al., 2004; Mishra and Flora, 2008). Chronic exposure to AS may lead to a variety of symptoms including skin pigmentation, numbness, hypertension, diabetes, cardiovascular disease, anemia, neurological disorders and liver and kidney diseases (Szymanska-Chabowska et al., 2002), whereas, acute AS exposure may cause nausea, vomiting, diarrhea, weakness, loss of appetite, shaking, cough, headache and neuropathy. AS is a known human carcinogen and causes various forms of malignancy and tumors of the skin, urinary bladder, liver, kidney and lung (Smith et al., 1992; Chen et al., 1992; Cui et al., 2006; Suzuki et al., 2008; Liu and Walkes, 2008). The health effects of toxic levels of AS are multidimensional in both human and animal populations (Nandi et al., 2006). Liver and kidneys are considered as the primary targets for its toxico-pathological manifestations, and there are reports of biochemical alterations indicative of hepatic and renal system involvement in AS toxicity in animals (Biswas et al., 1998; Santra et al., 1999). After ingestion, dissolved AS compounds are readily absorbed through the gastrointestinal tract and distributed in the blood to the liver, kidney, spleen, lung and many other organs; it affects nearly all organ systems of the body (Guha Majumdar, 2005). Epidemiological and animal studies have suggested potent mutagenic and carcinogenic abilities of AS (Brown and Kitchin, 1996; Chen and Shi, 2002), toxic and teratogenic effects in chick embryogenesis (Gilani and Alibhai, 1990). Experimental studies have also shown that AS exposure during pregnancy affects embryogenesis and offspring development in mice (Ma et al., 1994), rats (Zhang et al., 1997; 1999) and rodents (Wang et al., 2006).

More recently, the enhanced production of reactive oxygen species has been implicated to contribute to cell injury associated with AS exposure (Flora, 1999; Ramos et al., 1995). Indirect evidence of a role of oxidative stress in AS toxicity includes therapeutic and prophylactic efficacy of exogenously administered nutritional antioxidants such as ascorbic acid, a-tocopherol, methionine, thiamine and cysteine in acute and chronic AS toxicity in laboratory rats (Nandi et al., 2005; Flora, 1999; Ramanathan et al., 2002). Several mechanisms have been put forth to explain the mechanism of AS toxicity.

Zinc is a micronutrient as well as a trace element that is essential for a broad range of biological activities, and is nontoxic with the exception of a very high dose (Berthholf, 1988). Zinc is a fundamental element of more than 200 metalloenzymes and affects the activity and stability of many of them. Several studies have demonstrated the protective 
antioxidative role of zinc under various toxic conditions (Rostan et al., 2002; Sidhu et al., 2004a and b; Goel et al., 2005; Bhalla et al., 2007; Malhotra and Dhawan, 2008). Zinc is present in the brain at high concentrations and regulates many physiological functions (Singh et al., 1995; Goel et al., 2005). It is an essential catalytic or structural element of many proteins (Choi and Koh, 1998). Concentrated in synaptic vesicles, zinc is released during neuronal activity. Extracellular zinc modulates the activity of ion channels such as the NMDA receptors (Paoletti et al., 1997) and store-operated Ca2+ channels (Jan et al., 1999). Furthermore, the relevance of zinc in cognitive development and CNS homeostasis is well known (Takeda, 2001). In addition, zinc is also necessary to mobilize defenses against reactive oxygen species (ROS) and $\mathrm{H}_{2} \mathrm{O}_{2}$-induced apoptosis (Chung et al., 2005; Chung et al., 2006).

Therefore, it is important to explore the possibility of the protective potential of zinc in mitigating the adverse effects in the offspring of AS exposure during pregnancy, which would be a step forward in the management of patients who undergo AS poisoning. Furthermore, the present study may open new prospects for zinc to act as a nutritional and protective supplement for women during pregnancy to protect their offspring from the possible toxic effects of AS exposure during the perinatal period, which may ultimately prove beneficial for the health of the offspring by ameliorating adverse effects of AS. The present study has been designed to evaluate the effects of zinc on the perinatal toxicity of AS on the morphology and development of reflexes in mouse pups and on motor behavior and oxidative stress in the serum of male adolescent offspring.

\section{MATERIALS AND METHODS}

\section{Experimental animals}

Male and female Swiss-Webster strain mice (8-10 weeks old) were obtained from the animal husbandry of the College of Pharmacy, King Saud University, Riyadh, Saudi Arabia. The animals were housed in opaque plastic cages (three females and one male in each cage) under hygienic conditions in the animal facility of the Zoology Department, King Saud University, Riyadh, Saudi Arabia. All animals were maintained under reversed lighting conditions with white lights on from 22.30 to 10.30 hours local time. The ambient temperature was regulated between 18 and $22{ }^{\circ} \mathrm{C}$. After pregnancy (appearance of a vaginal plug was considered as day one of pregnancy), the males were removed from the cages and the females were subjected to experimental treatments. Food (laboratory animal diet, F-648, Grain Silos and Flour Mills Organization, Riyadh) and water were available ad libitum unless otherwise indicated. Only a trace quantity of zinc was present in this rat food according to the manufacturer. All procedures were carried out in accordance with the ethical guidelines for care and use of laboratory animals, and all protocols were approved by the local Ethics and Care of Experimental Animals Committee.

Pregnant female animals were divided into four groups with ten animals in each. Group I consisted of untreated mice and served as controls. Group II was treated with zinc in drinking water. Group III consisted of mice treated with AS in drinking water and Group IV consisted of mice coadministered with a mixture of AS and zinc.
Arsenic and Zinc administration

AS (sodium arsenate; analytical grade, Riedel de Haen, Germany) was dissolved in tap water in such a way that it resulted in a dose of $40 \mathrm{mg} / \mathrm{kg}$ body weight of the animal per day. After calculating the average volume of water consumed by the animals in one day, and by knowing the average body weight of the animals, AS was dissolved in tap water $(0.04 \mathrm{mg} /$ $\mathrm{ml}$ ) that resulted in a dose of $40 \mathrm{mg} / \mathrm{kg}$ body weight per day. Zinc was administered in the form of zinc sulfate (analytical grade, Riedel de Haen, Germany) in drinking water at a dose of $4 \% \mathrm{w} / \mathrm{v}$, which was equivalent to $40 \mathrm{mg} / \mathrm{kg}$ body weight per day. These AS and zinc doses formed the only drinking fluid source for the experimental groups of dams during the perinatal period of the experiment. Our pilot studies used two (20 and $40 \mathrm{mg} / \mathrm{kg}$ ) doses of AS and zinc; these two doses are within the ranges of doses reported in published literature. It was observed in our pilot studies that the higher dose (40 mg/ $\mathrm{kg}$ ) inflicted maximum effects in the animals in comparison to the lower dose of $20 \mathrm{mg} / \mathrm{kg}$ (data not shown). Thus only the highest effective doses of zinc and AS were selected for the present study. Furthermore, our pilot studies did not show any reaction or precipitation upon mixing the zinc and AS salts together in a single bottle. Thus for the mixture of zinc and AS we used zinc and AS dissolved in the same bottle for the administration as the drinking fluid. Treatment of mothers started from day one of pregnancy and was continued until postnatal day 15 (PD15) after birth of the offspring and thereafter the mothers were switched to plain tap water. All pregnant mice were housed individually. The drinking fluid containing AS and/or zinc doses was changed to fresh preparations every third day. The control group received plain tap water only.

\section{Behavioral observations}

On the day of birth (postnatal day 0, PD0) the pups were culled to only eight per dam and were left with their mothers until PD22. During this weaning period, three pups of each litter were color marked at random (without consideration of gender) and were subjected to various behavioral tests (described below) under dim light (ca 8 lux). In all, 21 pups belonging to seven litters from each treatment category were considered. For statistical analysis, the mean of all three color marked pups per litter was considered as a single score. Thus seven replicates from each treatment category were considered in these observations. All observations were recorded on PD1 and repeated every other day until PD21 in the same three color-marked pups of each litter. These observations were used to measure the early development of sensory motor coordination reflexes together with morphological development in the pups.

Body weight:

The pups were weighed every other day from PD1 until PD21.

Righting reflex:

The time taken by a pup placed on its back to turn over and place all four paws on the substrate was recorded. An upper limit of 2 min was set for this test. 
Cliff avoidance activity:

Pups were placed on the edge of a table top with the forepaws and face over the edge. The time taken by the pups to back away and turn from the "cliff" was recorded. Again an upper limit of 2 min was chosen. A latency of 2 min was attributed when the animal fell from the "cliff".

Rotating reflex:

The surface used to measure the rotating reflex was the same as that used for the righting reflex, except that it was inclined at an angle of $30^{\circ}$. The pups were placed on this surface with their heads pointed downwards. The time elapsed until the pup rotated its body through $180^{\circ}$ geonegatively and faced its head upwards was recorded as the rotating time. The upper limit of this test was also set at $2 \mathrm{~min}$.

Eye opening and hair appearance:

The days at which the body hair fuzz appeared and the eyes opened were also recorded.

Motor Tests of young adult males:

The offspring were weaned on PD21, after which the males were separated and kept in groups of two or three. Subsequently, 10 males from each treated group (including representatives from each of the 7 litters) were subjected to motor activity tests. The young adult males were placed in an experimental wooden arena measuring $80 \times 80 \times 30 \mathrm{~cm}$ and the floor was divided into 64 squares of equal size. Various behavioral elements were observed as described by Ajarem (1987 and Ajarem and Ahmad (1991). Elements of locomotor activity included the number of squares crossed, wall rears, rears and washes, as well as the duration of locomotion and immobility. These visual observations in the arena lasted for $300 \mathrm{sec}$ for each animal.

\section{Biochemical study}

At the age of PD21, one male pup was chosen from each litter, apart from the three color-marked pups that were used for the behavioral tests. Thus seven offspring from each experimental group were sacrificed by decapitation and their blood was collected using EDTA as the anticoagulant. The blood samples were centrifuged at $1000 \mathrm{~g}$ for $10 \mathrm{~min}$ and the clear non-hemolyzed supernatant (plasma or serum) was used for various biochemical estimations.

$\gamma$-glutamyl transferase $(\gamma-G T)$ :

The enzyme $\gamma$-glutamyl transferase was assayed by the method described in Kit No.GT1065 of Randox, U.K., based on the principle of Szasz (1969). The specific activity was expressed as Units per liter $(\mathrm{U} / 1)$.

Reduced glutathione (GSH):

Reduced glutathione (GSH) content was estimated according to the method of Ellman (1959). Briefly, $0.1 \mathrm{ml}$ of $25 \%$ trichloroacetic acid was added to $0.5 \mathrm{ml}$ of plasma. After protein precipitation by trichloroacetic acid, the samples were centrifuged to obtain the supernatant. Then $0.1 \mathrm{ml}$ of the supernatant was incubated with $2.0 \mathrm{ml}$ of freshly prepared (0.6 mmol/l) 5, 5 - dithiobis (2-nitrobenzoicacid). The optical density of the yellow complex was measured at $412 \mathrm{~nm}$ against a reference lacking plasma. For each set of assays, a standard curve was obtained for reduced glutathione (GSH) and used to calculate GSH content in serum from samples.

Lipid peroxidation (TBARS):

Lipid peroxidation (TBARS) was assayed using the method of Ohkawa et al. (1979). Briefly, a mixture of $8 \%$ solvent sodium dodecyl sulfate $(0.2 \mathrm{ml}), 0.9 \%$ TBA (thiobarbituricacid; $0.2 \mathrm{ml}$ ), and $20 \%$ acetic acid $(1.5 \mathrm{ml})$ was prepared, to which $0.2 \mathrm{ml}$ of plasma was added and the volume was made up to $4 \mathrm{ml}$ by adding distilled water. After boiling for 1 hour the mixture was cooled, and $5 \mathrm{ml}$ of solution of $\mathrm{n}$-butanol + pyridine ( $\mathrm{vol} / \mathrm{vol}$ 15:1) was added and then centrifuged at $1000 \mathrm{~g}$ for 15 minutes, Absorbance in the supernatant was measured at $532 \mathrm{~nm}$ using a spectrophotometer.

\section{Protein:}

Protein concentrations were measured by the method of Lowry et al. (1951). Briefly, the samples were diluted with $100 \mathrm{mmol} / 1$ phosphate buffer (pH7.5) to a volume of $0.5 \mathrm{ml}$. The reactions were diluted with $0.5 \mathrm{ml} 1.0 \mathrm{~N}$ sodium hydroxide followed by the addition of $5.0 \mathrm{ml}$ reagent mixture (containing $48 \mathrm{ml}$ $2 \%$ sodium carbonate, $1 \mathrm{ml} \mathrm{1 \%}$ copper sulfate and $1.0 \mathrm{ml} 2 \%$ sodium potassium tartarate). After 10 minutes of incubation at room temperature, the color was developed by the addition of $1.0 \mathrm{~N}$ Folin's reagent, and absorbance was measured using a spectrophotometer at $750 \mathrm{~nm}$.

\section{Statistical analysis:}

The data were compared between the experimental groups by the analysis of variance (ANOVA) using a minitab computer program, and were subsequently analyzed by Student's t-test (Yamane , 1973), except the data of the motor test that was analyzed using the Mann-Whitney U test (Sokal and Rohlfe, 1981).

\section{RESULTS}

The body weight of the AS treated pups lagged behind their controls from the day of their birth (PD1) and remained so throughout almost all their weaning period until PD21. A significant decline in the body weight of the treated pups was observed on PD7, PD14 and PD21 (Fig. 1). Zinc alone had no effect on the body weight compared to the control. In contrast, zinc in combination with AS had a significant $(\mathrm{p}<0.05)$ protective effect on body weight compared to the arsenic group (Fig. 1).

Morphological development such as eye opening and body hair appearance were also affected by AS treatment (Fig.2). Both of these morphological parameters in the AS treated pups were significantly $(\mathrm{p}<0.05)$ delayed compared to the controls. Zinc alone had no effect whereas zinc in combination with AS had a significant $(\mathrm{p}<0.05)$ reduction in the delay of eye opening 


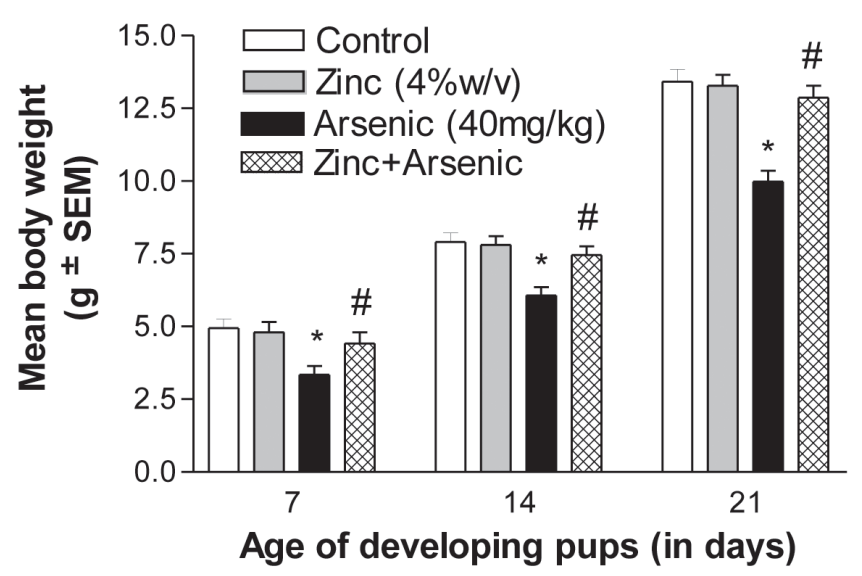

Figure 1. Effect of perinatal oral exposure to zinc $(4 \% w / v)$ and arsenic ( $40 \mathrm{mg} / \mathrm{kg}$ body weight), independently and in combination in drinking water on the body weight gain of the developing pups on post natal day7 (PD7), PD14 and PD21 (weaning period). Fresh zinc and arsenic doses formed the only available drinking fluid to the dams $24 \mathrm{~h}$ from day one of pregnancy until PD15 after birth of the offspring (perinatal exposure period), after which the dams were switched to plain tap drinking water.

* represents statistically significant $(p<0.05)$ depletion as compared to the control and \# represents significant $(p<0.05)$ amelioration in body weight decline compared to the arsenic alone treated group by Newman Keul's student's $t$ test after oneway ANOVA.

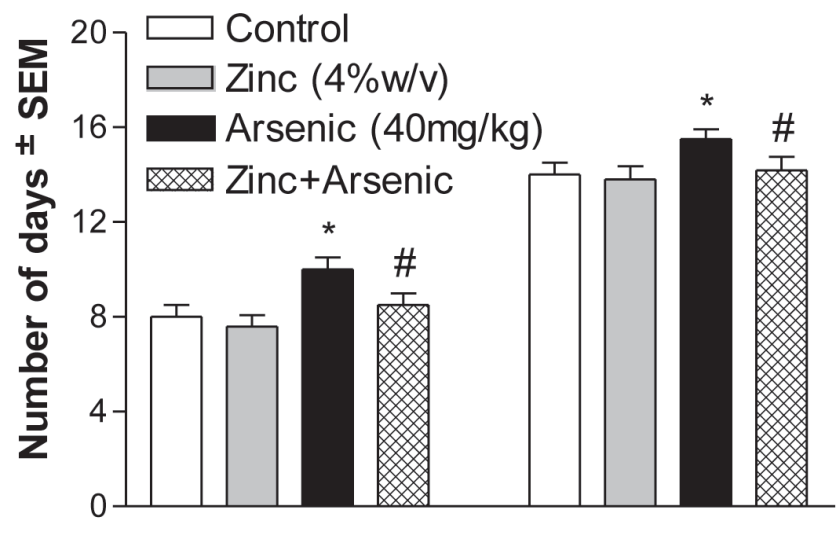

Hair appearance

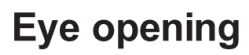

Figure 2. Effect of perinatal oral exposure to zinc (4\%w/v) and arsenic (40mg/kg body weight), independently and in combination in drinking water on the body hair fuzz appearance and opening of the eyes in the postnatal developing pups. Fresh zinc and arsenic doses formed the only available drinking fluid to the dams $24 \mathrm{~h}$ from day one of pregnancy until PD15 after birth of the offspring (perinatal exposure period), after which the dams were switched to plain tap drinking water.

* represents statistically significant $(p<0.05)$ delay as compared to the control and \# represents significant $(p<0.05)$ amelioration in body hair fuzz appearance and opening of the eyes compared to the arsenic alone treated groups by Newman Keul's student's $t$ test after one way ANOVA.

\section{TABLE 1}

Effect of perinatal oral exposure to zinc ${ }^{\mathrm{a}}$ and arsenic ${ }^{\mathrm{b}}$ independently and in combination in drinking water on the motor activity of male adolescent offspring (post natal day 22)

\begin{tabular}{|c|c|c|c|c|c|c|}
\hline \multirow[b]{2}{*}{$\begin{array}{l}\text { Treatment } \\
\text { Groups }\end{array}$} & \multicolumn{6}{|c|}{ Median number (with ranges) of acts and postures } \\
\hline & $\begin{array}{c}\text { Number of } \\
\text { squares crossed }\end{array}$ & Wall rears & Rears & Wash & $\begin{array}{l}\text { Movement } \\
\text { duration } \\
\text { (sec) }\end{array}$ & $\begin{array}{c}\text { Immobility } \\
\text { duration } \\
\text { (sec) }\end{array}$ \\
\hline Control & $\begin{array}{c}371 \\
(314-409)\end{array}$ & $\begin{array}{c}33 \\
(28-41)\end{array}$ & $\begin{array}{c}15 \\
(11-22)\end{array}$ & $\begin{array}{c}6 \\
(3-10)\end{array}$ & $\begin{array}{c}226.5 \\
(192.5-288.5)\end{array}$ & $\begin{array}{c}73.5 \\
(12-108)\end{array}$ \\
\hline $\begin{array}{c}\text { Zinc } \\
(4 \% \mathrm{w} / \mathrm{v})\end{array}$ & $\begin{array}{c}338 \\
(298-387)\end{array}$ & $\begin{array}{c}30 \\
(25-40)\end{array}$ & $\begin{array}{c}11 \\
(9-19)\end{array}$ & $\begin{array}{c}5 \\
(4-9)\end{array}$ & $\begin{array}{c}238 \\
(184.5-290)\end{array}$ & $\begin{array}{c}62 \\
(10-115.5)\end{array}$ \\
\hline $\begin{array}{l}\text { Arsenic } \\
(40 \mathrm{mg} / \mathrm{kg})\end{array}$ & $\begin{array}{c}128^{* *} \\
(87-193)\end{array}$ & $\begin{array}{c}9^{* *} \\
(4-15)\end{array}$ & $\begin{array}{c}5^{* \star} \\
(0-9)\end{array}$ & $\begin{array}{c}7 \\
(4-11)\end{array}$ & $\begin{array}{c}92.5^{* * *} \\
(78.5-122.5)\end{array}$ & $\begin{array}{c}208^{* * *} \\
(177.5-221.5)\end{array}$ \\
\hline $\begin{array}{c}\text { Zinc + } \\
\text { Arsenic }\end{array}$ & $\begin{array}{c}256^{\# \#} \\
(183-317)\end{array}$ & $\begin{array}{c}24^{\# \#} \\
(19-35)\end{array}$ & $\begin{array}{c}10^{\# \#} \\
(8-18)\end{array}$ & $\begin{array}{c}6 \\
(2-9)\end{array}$ & $\begin{array}{c}196^{\# \#} \\
(149.5-263.5)\end{array}$ & $\begin{array}{c}104.5^{\# \#} \\
(36.5-150.5)\end{array}$ \\
\hline
\end{tabular}

** and *** significantly different $(P<0.01$ and $P<0.001$ respectively) from the control by Mann-Whitney $U$ test. \#\# significantly different $(P<0.01)$ from the arsenic alone treated offspring by the Mann-Whitney $U$ test. a and b Fresh zinc and arsenic doses formed the sole available drinking fluid to the dams from day one of pregnancy until PD15 after birth of the offspring (perinatal exposure period), after which the dams were switched to plain tap drinking water. 
and body hair appearance compared to the AS alone group (Fig. 2).

Perinatal exposure of mice to AS had a significant effect on the early development of all sensory motor reflexes in the pups studied here. Pups born to treated mothers were lethargic and sluggish from the very first day (PD1). During the first two weeks of postnatal development AS had significant $(p<0.05)$ suppressive effect on the righting reflex and cliff avoidance activity, as shown in Fig. 3 and 4, respectively, whereas the rotating reflex (Fig.5) was significantly $(\mathrm{p}<0.05)$ suppressed only during the first week of postnatal development. Exposure to zinc alone had no significant effect on these reflexes and resembled the control animals. However, zinc in combination with AS reduced the suppressive effects significantly $(\mathrm{p}<0.05)$ compared to the AS alone group in all the developing sensory motor reflexes of the pups (Figs. 3, 4 and 5).

The locomotor activity test (Table 1) showed that perinatal AS exposure affected almost all the elements of acts and postures of the male offspring. The number of squares crossed, wall rears, rears and movement duration decreased significantly $(p<0.05)$, whereas the duration of immobility increased significantly $(\mathrm{p}<0.05)$ in the AS treated animals compared to the controls. Exposure to zinc alone had no effect on any of the parameters. However, zinc in combination with AS increased significantly $(\mathrm{P}<0.05)$ all locomotor parameters compared to the offspring exposed to AS alone (Table 1) and was able to bring the affected behavioral activities within the normal untreated control range (Table 1).

The level of $\gamma$-glutamyltransferase (GGT) activity in the plasma of the male offspring was significantly increased

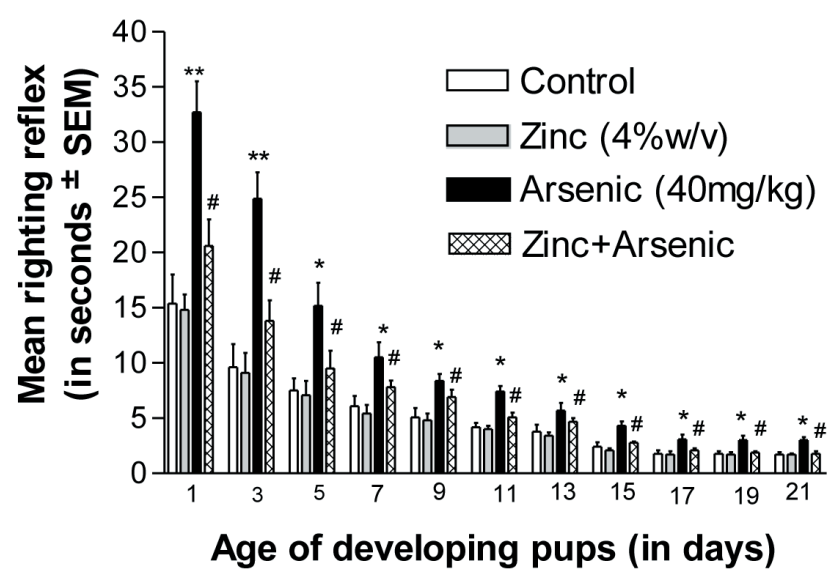

Figure 3. Effect of perinatal oral exposure to zinc (4\%w/v) and arsenic ( $40 \mathrm{mg} / \mathrm{kg}$ body weight), independently and in combination in drinking water on the mean righting reflex of the developing pups from post natal day1 (PD1) until PD21 (weaning period). Fresh zinc and arsenic doses formed the only available drinking fluid to the dams $24 \mathrm{~h}$ from day one of pregnancy until PD15 after birth of the offspring (perinatal exposure period), eafter which the dams were switched to plain tap drinking water.

${ }^{*}$ and ${ }^{* *}$ represent statistically significant $(\mathrm{p}<0.05$ and $\mathrm{p}<0.01$ respectively) delay in righting reflex as compared to the control and \# represents significant $(p<0.05)$ amelioration in delay of righting reflex development

compared to the arsenic alone treated groups by Newman Keul's student's t test after one way ANOVA.

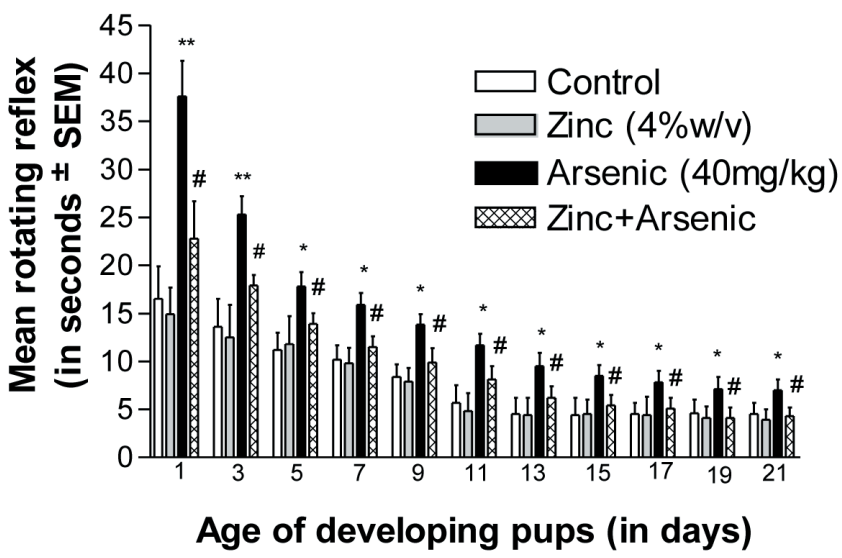

Figure 4. Effect of perinatal oral exposure to zinc (4\%w/v) and arsenic ( $40 \mathrm{mg} / \mathrm{kg}$ body weight), independently and in combination in drinking water on the mean rotating reflex of the developing pups from post natal day1 (PD1) until PD21 (weaning period). Fresh zinc and arsenic doses formed the only available drinking fluid to the dams $24 \mathrm{~h}$ from day one of pregnancy until PD15 after birth of the offspring (perinatal exposure period), after which the dams were switched to plain tap drinking water.

$*$ and ${ }^{* *}$ represent statistically significant $(\mathrm{p}<0.05$ and $\mathrm{p}<0.01$ respectively) delay in righting reflex as compared to the control and \# represents significant $(p<0.05)$ amelioration in delay of rotating reflex development compared to the arsenic alone treated groups by Newman Keul's student's t test after one way ANOVA.

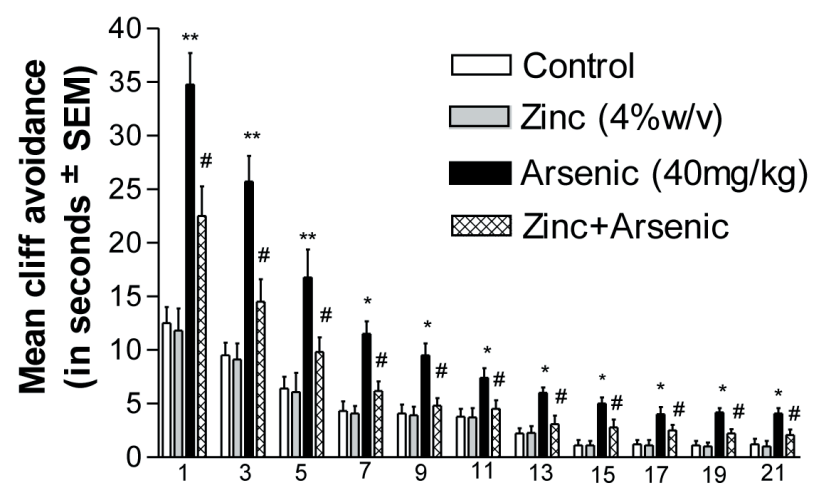

Age of developing pups (in days)

Figure 5. Effect of perinatal oral exposure to zinc $(4 \% w / v)$ and arsenic $(40 \mathrm{mg} / \mathrm{kg}$ body weight), independently and in combination in drinking water on the mean cliff avoidance reflex of the developing pups from post natal day 1 (PD1) until PD21 (weaning period). Fresh zinc and arsenic doses formed the only available drinking fluid to the dams $24 \mathrm{~h}$ from day one of pregnancy until PD15 after birth of the offspring (perinatal exposure period), after which the dams were switched to plain tap drinking water.

* and ${ }^{* *}$ represent statistically significant $(p<0.05$ and $p<0.01$ respectively) delay in avoidance of the cliff reflex as compared to the control and \# represents significant $(p<0.05)$ amelioration in delay of the cliff avoidance reflex development compared to the arsenic alone treated groups by Newman Keul's student's $t$ test after one way ANOVA. 


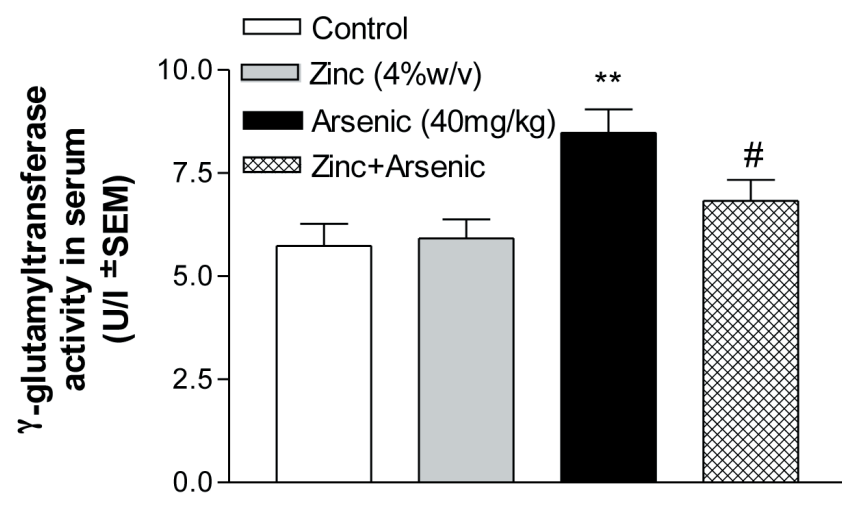

Treatment Groups

Figure 6. Effect of perinatal oral exposure to zinc $(4 \% \mathrm{w} / \mathrm{v})$ and arsenic (40mg/kg body weight), independently and in combination in drinking water on the $\gamma$ glutamyltransferase (GGT) activity in the serum of the male adolescent offspring. Fresh zinc and arsenic doses formed the only available drinking fluid to the dams 24h from day one of pregnancy until PD15 after birth of the offspring (perinatal exposure period), after which the dams were switched to plain tap drinking water.

** represents statistically significant $(p<0.01)$ increase in GGT activity as compared to the control and \# represents significant $(p<0.05)$ amelioration in GGT activity stimulation by bringing back the level of GGT to the level of The control group as compared to the arsenic alone treated group by Newman Keul's student's $t$ test after one way ANOVA.

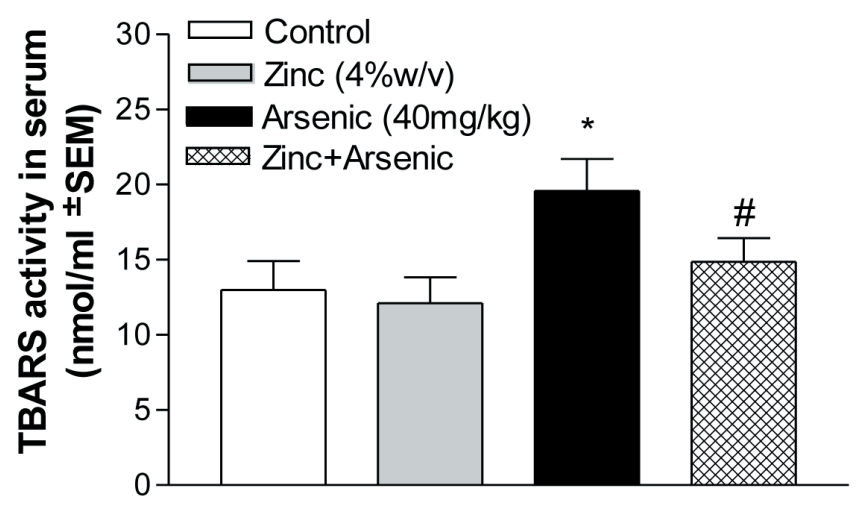

Treatment Groups

Figure 7. Effect of perinatal oral exposure to zinc (4\%w/v) and arsenic ( $40 \mathrm{mg} / \mathrm{kg}$ body weight), independently and in combination in drinking water on the oxidative stress enzyme lipid peroxidation (TBARS) activity in the serum of the male adolescent offspring. Fresh zinc and arsenic doses formed the only available drinking fluid to the dams $24 \mathrm{~h}$ from day one of pregnancy until PD15 after birth of the offspring (perinatal exposure period), eafterwhich the dams were switched to plain tap drinking water.

* represents statistically significant $(p<0.05)$ increase in TBARS activity compared to the control and \# represents significant ( $p$ 0.05) amelioration in TBARS activity stimulation by bringing back the level of TBARS to the level of the control group compared to the arsenic alone treated group by Newman Keul's student's $t$ test after one way ANOVA. after perinatal exposure to AS (Fig. 6). Administration of zinc along with AS led to a significant decrease in the level of GGT compared to the AS alone treatment group and was able to bring the raised level of GGT to within the normal untreated control range (Fig. 6).

TBARS level showed a significant increase $(p<0.05)$ in the plasma of the male offspring exposed perinatally to AS (Fig. 7). However, perinatal administration of zinc along with AS led to a significant decrease $(p<0.05)$ in the level of TBARS compared to the AS alone treatment group and was able to raise the level of TBARS to within normal untreated control range (Fig. 7). The level of GSH was significantly decreased $(\mathrm{p}<0.05)$ in the blood serum after perinatal AS exposure (Fig. 8) c whereas perinatal exposure to zinc alone was ineffective on GSH level, but exposure to zinc in combination with AS was able to increase significantly $(p<0.05)$ the GSH level compared to the AS alone exposed offspring, and was effective in restoring the decreased level of GSH within the normal control range (Fig. 8).

\section{DISCUSSION}

The present results suggest that perinatal exposure to AS is toxic to the offspring and influences their postnatal developing morphology and sensory motor reflexes during the weaning period, and also their motor behavioral activities and the levels of GGT enzyme and TBARS and GSH activities (causing oxidative stress) in the serum of the adolescent offspring. However, animals exposed to AS in the presence of

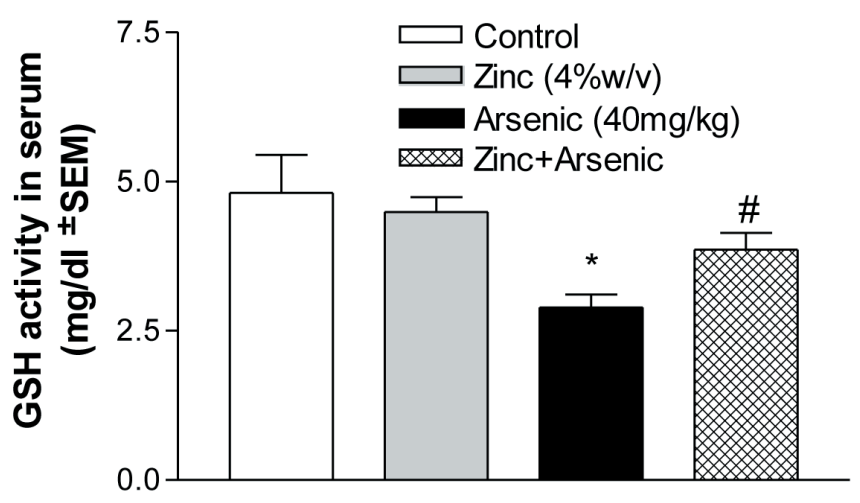

Treatment Groups

Figure 8. Effect of perinatal oral exposure to zinc (4\%w/v) and arsenic ( $40 \mathrm{mg} / \mathrm{kg}$ body weight), independently and in combination in drinking water on the oxidative stress enzyme reduced glutathione (GSH) activity in the serum of the male adolescent offspring. Fresh zinc and arsenic doses formed the only available drinking fluid to the dams $24 \mathrm{~h}$ from day one of pregnancy until PD15 after birth of the offspring (perinatal exposure period), after which the dams were switched to plain tap drinking water.

* represents statistically significant $(p<0.05)$ decrease in GSH activity compared to the control and \# represents significant $(p<0.05)$ amelioration in GSH activity depletion by restoring the level of GSH to the level of the control group compared to the arsenic alone treated group by Newman Keul's student's $t$ test after one way ANOVA 
zinc showed a remarkable ameliorating effect of zinc on the AS toxicity since these offspring did not exhibit significant behavioral or biochemical deficits compared to the groups exposed to AS alone. Furthermore, the ineffectiveness of zinc alone to inflict any behavioral or biochemical change suggests the non-toxicity of zinc itself in the animals.

Body weight, body hair appearance and opening of the eyes can serve as useful indicators of morphological developments in animals. The postnatal depletion in body weight and the delay in the appearance of the body hair and opening of the eyes in the AS-exposed pups may be indicative of lasting AS - induced postnatal effects in the pups. It has been shown experimentally that perinatal exposure to AS affects embryonic and offspring development in mice (Ma et al., 1994), rats (Zhang et al., 1997; 1999) and rodents (Wang et al., 2006).

Perinatal AS exposure suppressed the preweaning reflexes in the developing mouse pups. Such decreases in early nerve reflex and neurobehavioral development of the rodent offspring due to AS exposure have been reported earlier also (Ma et al., 1994; Zhang et al., 1999). This suggests a direct intervention of AS in the developing pups in utero. At the same time, it is also likely that the pups received AS via their mother's milk during lactation. It is now well documented that significant quantities of compounds that are given to the mothers during late pregnancy may be transmitted to the offspring in utero and / or via mother's milk during lactation (Ajarem and Ahmad, 1991, 1998; Draski et al., 1989; Mereu et al., 1987). Furthermore, the suppressing effects of AS on the motor behavior of the offspring at the early adolescent stage suggest a deleterious effect and significant hypo activity brought about by perinatal AS exposure. Exposure to zinc alone caused no alteration in any of the observed behavioral parameters and resembled the control offspring, whereas exposure to zinc in combination with AS had an ameliorating effect on all observed behavioral parameters by reducing the intensity of the deleterious effects of AS alone and by bringing behavior back within the control range. Thus it indicates that zinc has a protective effect on the morphological, motor sensory reflexes and motor behavioral activities by modulating the adverse effects on the offspring of perinatal AS exposure.

The biochemical results in the present study suggest that GGT and the oxidative stress parameters of TBARS and GSH may serve as reliable biomarkers for detecting teratological and/or behavioral effects of AS toxicity in experimental models. These biomarkers are significantly altered in the serum of the offspring when their mothers are exposed to AS during the perinatal period. It is pertinent to note here that Kaltreider et al. (2001) reported that extremely low levels of AS exposure can cause cell damage or toxicity and alter hormonal functions in the glucocorticoid system which is centrally involved in the control of growth, glucose regulation and protein metabolism (Vahter et al., 2002). Thus perinatal exposure to AS during pregnancy may result in the oxidative stress which ultimately may have resulted in the altered behavioral expressions. Zinc alone in the present study did not affect any of the biomarkers, however, zinc in combination with AS was significantly effective in ameliorating the deleterious effects of AS alone on GGT, TBARS and GSH. This shows that zinc administration results in a reversal in indicators of oxidative stress and may have a role in reducing the toxicity of AS. Interestingly, Fascineli et al. (2002) reported that zinc did not improve AS teratogenesis in their in vivo and in vitro studies. This might be due to the differences in the salt form of AS used in their studies. However, further studies including other oxidative stress parameters are required to ensure the antioxidative role of zinc in ameliorating the toxicity of AS. Several studies have demonstrated the antioxidative role of zinc under various toxic conditions (Rostan et al., 2004). The protective potential of zinc has been evaluated under other toxic conditions also (Sidhu et al., 2004 a, b; Goel et al., 2005; Bhalla et al., 2007; Malhotra and Dhawan, 2008). Extracellular zinc modulates the activity of ion channels of various receptors (Paoletti et al., 1997; Jan et al., 1999; Choi et al., 2001). Furthermore, the relevance of zinc in CNS homeostasis is well known (Takeda, 2001). According to the present study, zinc consumed during the perinatal period of pregnancy can ameliorate the possible toxicity of AS exposure in the offspring.

\section{CONCLUSION}

The present study, together with the supporting literature, clearly suggest that AS toxicity in pregnant females may have significant ill health effects on the embryonic development of their offspring, from the toxicological, behavioral and biochemical points of view. Perinatal exposure to AS is toxic to the offspring and influences their postnatal developing morphology and sensory motor reflexes during the weaning period, and also their motor behavioral activities and the levels of GGT and oxidative stress indices such as TBARS and GSH activity in the serum of the adolescent offspring. Animals exposed to AS in presence of zinc show a remarkable ameliorating effect of zinc on the AS toxicity since such offspring did not exhibit significant behavioral or biochemical deficits compared to the group exposed to AS alone. Furthermore, the ineffectiveness of zinc alone to inflict any behavioral or biochemical effect clearly suggests the ameliorating effect of zinc on the behavioral and biochemical toxicity of AS, and it can be a useful supplement for protecting against possible AS toxicity during pregnancy.

\section{ACKNOWLEDGEMENTS}

The authors extend their appreciation to the Deanship of Scientific Research at King Saud University for funding the work through the research group project No. RGP-VPP-284.

\section{REFERENCES}

AJAREM JS (1987). Studies on the effect of alcohol on locomotor activity and immobility in male mice. Proc Saudi Biol Soc 10: 97-104.

AJAREM JS, AHMAD M (1991) Behavioral and biochemical consequences of perinatal exposure of mice to instant coffee: a correlative evaluation. Pharmacol Biochem Behav 40: 847- 852.

AJAREM JS, AHMAD M (1998) Prenatal nicotine exposure modifies behavior of mice through early development. Pharmacol Biochem Behav 59: 313318.

BERTHHOLF RL (1988) Zinc. In: SEILER HG, SIGEL H (eds) Handbook on toxicity of Inorganic compounds. Marcel Dekker, New York, pp. 787- 800.

BHALLA P, CHADHA VD, DHAWAN DK (2007) Effectiveness of zinc in modulating lithium induced biochemical and behavioral changes in rat brain. Cell Mol Neurobiol 27 : 595-607.

BISWAS D, BANERJEE M, SEN G, DAS JK, BANERJEE A, SAU TJ, PANDIT S, GIRI AK, BISWAS T (2008) Mechanism of erythrocyte death in human population exposed to arsenic through drinking water. Toxicol Appl Pharmacol 230: 57-66.

BROWN JL KITCHIN KT (1996) Arsenite, but not cadmium, induces ornithine decarboxylase and heme oxygenase activity in rat liver:relevance to arsenic carcinogenesis. Cancer Lett 98: 227-231. 
CHEN CJ, CHEN CW, WU MM KUO TL (1992) Cancer potential in liver, lung bladder and kidney due to ingested inorganic arsenic in drinking water. Br J Cancer 66: 888-892.

CHEN F, SHI X (2002) Intracellular signal transduction of cells in response to carcinogenic metals. Crit. Rev Oncol Hematol 42: 105 - 121.

CHOI DW, KOH JY (1998) Zinc and brain injury. Annu Rev Neurosci 21: 347- 75.

CHUNG MJ, WALKER PA, BROWN RW, HOGSTRAND C (2005) Zincmediated gene expression offers protection against $\mathrm{H} 2 \mathrm{O} 2$-Induced cytotoxicity. Toxicol Appl Pharmacol 205: 225-236.

CHUNG MJ, WALKER PA, HOGSTRAND C (2006) Dietary phenolicantioxidants, caffeic acid and Trolox, protect rainbow trout gill cells from nitric oxide-induced apoptosis. Aquat Toxicol 80: 321-328.

CUI $X$, WAKAI T, SHIRAI Y, YOKOYAMA N, HATAKEYAMA K, HIRANO S (2006) Arsenic trioxide inhibits DNA methyltransferase and restores methylation-silenced genes in human liver cancer cells. Hum Pathol 37: 298-311.

DRASKI LJ, BURRIGHT RG, DONOVICK PJ (1989) The influence of prenatal and/or postnatal exposure to lead on behavior of preweaniling mice. Physiol Behav 45: 711-715.

ELLMAN G (1959). Tissue sulfhydryl groups. Arch Biochem Biophys 82: 70-77.

FASCINELI ML, HUNTER ES $3^{\text {rd }}$, KEMPINAS W De Grava (2002) Fetotoxicity caused by the interaction between zinc and arsenic in mice. Teratog Carcinog Mutagen 22: 315 - 327.

FLORA SJ (1999) Arsenic-induced oxidative stress and its reversibility following combined administration of $\mathrm{N}$-acetylcysteine and meso 2,3dimercaptosuccinic acid in rats. Clin Exp Pharmacol Physiol 26: 865-869.

FRISBIE SH, ORTEGA R, MAYNARD DM, SARKAR B (2002) The concentrations of arsenic and other toxic elements in Bangladesh's drinking water. Environ Health Perspect 10: 1147-1153.

GHATAK S, BISWAS A, DHALI GK, CHOWDHURY A, BOYER JL, SANTRA A (2011) Oxidative stress and hepatic stellate cell activation are key events in arsenic induced liver fibrosis in mice. Toxicol Appl Pharmacol 25: 59-69.

GILANI SH, ALIBHAI Y (1990) Teratogenicity of metals to chick embryos. J Toxicol Environ Health 30: 23-31.

GOEL A, DANI V, DHAWAN DK (2005) Protective effects of zinc on lipid peroxidation, antioxidant enzymes and hepatic histoarchitecture in chlorpyrifos-induced toxicity. Chem Biol Interaction 156: 131-140.

GUHA MAZUMDER DN (2007) Arsenic and non-malignant lung disease. J Environ Sci Health A Tox Hazard Subst Environ Eng 42: 1859-1867.

JAN C R, WU SN, TSENG CJ (1999) Zn2+ increases resting cytosolic $\mathrm{Ca} 2+$ level and abolishes capacitative Ca2+ entry induced by ATP in MDCK cells. Naunyn Schmiedegergs Arch Pharmacol 360: 249-259.

JIN Y, SUN G, LI X, LI G, LU C, QU L (2004) Study on the toxic effects Induced by different arsenicals in primary cultured rat astroglia. Toxicol Appl Pharmacol 196: 396-403.

KALTREIDER RC, DAVIS AM, LARIVIERE JP, HAMILTON JW (2001) Arsenic alters the function of the glucocorticoid receptor as a transcription factor. Environ Health Perspect 109: 245-251.

LIU J, WAALKES MP (2008) Liver is a target of arsenic carcinogenesis. Toxicol Sci 105: 24-32.

LOWRY OH, ROSEBROUGH NJ, FARR AL, RANDALL RJ (1951) Protein measurement with Folin phenol reagent. J Biol Chem 193: 265-275.

MA L, ZHANG C, LIU WJ (1994) Effects of arsenic on the offspring development in mice. Zhonghua Yu Fang Yi Xue Za Zhi 28: 20-23.

MALHOTRA A, DHAWAN DK (2008) Zinc improves antioxidative enzymes in red blood cells and hematology in lithium-treated rats. Nutr Res 28 : 43-50.

MEREU GI, YOON KWP, BOI V (1987) Preferential stimulation of ventral tegmental area dopaminergic neurons by nicotine. Eur J Pharmacol 141: 395-399.

MISHRA D, FLORA SJ (2008) Differential oxidative stress and DNA damage in rat brain regions and blood flowing chronic arsenic exposure. Toxicol Ind Health 24: 247-256.

NANDI D, PATRA RC, SWARUP D (2005) Effect of cysteine, methionine, ascorbic acid and thiamine on arsenic-induced oxidative-stress and biochemical alterations in rats. Toxicology 211: 26-35.
NANDI D, PATRA RC, SWARUP D (2006) Oxidative stress indices and plasma biochemical parameters during oral esposure to arsenic in rats. Food Chem Toxicol 44: 1579-1584.

OHKAWA H, OHISSHI N, YAGI K (1979) Assay for lipid peroxides in animal tissues by thiobarbituric acid reaction. Anal Biochem 95: 351-358.

PAOLETTI P, ASCHER P, NEYTON J (1997) High - affinity zinc inhibition of NMDA NR1 - NR2A receptors. J Neurosci 17: 5711-5725.

RAMANATHAN K, BALAKUMAR BS, PANEERSELVAM C (2002) Effects of ascorbic acid and alpha-tocopherol on arsenic-induced oxidative stress. Hum Exp Toxicol 21: 675-680.

RAMOS O, CARRIZALES L, YANEZ L, MEJIA J, BATRES L, ORTIZ D, DIAZ-BARRIGA F (1995) Arsenic increased lipid peroxidation in rat tissues by a mechanism independent of glutathione levelas. Environ Health Perspect 103: 85-88.

ROSTAN EF, DEBYS HV, MADEY DL, PINNEL SR (2002) Evidence supporting zinc as an important antioxidant for skin. Int. J. Dermatol., 41: 606-611.

SANTRA A, CHOWDHURY A, GHATAK S, BISWAS A, DHALI GK (2007) Arsenic induces apoptosis in mouse liver is mitochondria dependent and is abrogated by N-acetylcysteine. Toxicol Appl Pharmacol 220: 146155.

SANTRA A, DAS GUPTA J, DE BK, ROY B, GUHA MAZUMDER DN (1999) Hepatic manifestations in chronic arsenic toxicity. Indian J. Gastroenterol., 18: 152-155.

SIDHU P, GARG ML, DHAWAN DK (2004a) Protective role of zinc in nickel induced hepatotoxicity in rats. Chem. Biol. Interact., 150: 199-209.

SIDHU P, GARG ML, DHAWAN DK (2004b) Protective effects of zinc on oxidative stress enzymes in liver of protein deficient rats. Nutr. Hosp., 19: 341-347.

SINGH B, DHAWAN D, CHAND B, SINGH N, MANGAL RC, TREHAN PM (1995) Trace element distribution in rat brain following lead and lithium supplementation-a study using an EDXRF spectrophotometer. Appl Rad Isotope 46: 59-64.

SMITH AH, HOPENHAYN-RICH C, BATES MN, GOEDEN HM, HERTZPICCIOTTO I, DUGGAN MH, WOOD R, KOSNETT MJ, SMITH MT (1992) Cancer risks from arsenic in drinking water. Environ. Health Perspect., 97: 259-267.

SOKAL RR, ROHLFE FJ (1981) Biometry: The principles and practice of statistics in biological research. W.H. Freeman WH: San Francisco.

SUZUKI S, ARNOLD LL, MUIRHEAD D, LU X, LE XC, BJORK JA, WALLACE KB, OHNISHI T, KAKIUCHI-KIYOTA S, PENNINGTON KL, COHEN SM (2008) Inorganic arsenic-induced intramitrochondrial granules in mouse urothelium. Toxicol Pathol 36: 999-1005.

SZASZ G (1969) A kinetic photometric method for serum gamma-glutamyl transpeptidase. Clin Chem 15: 124-136.

SZYMANSKA-CHABOWSKA A, ANTONOWICZ-JUCHIEWICZ J, ANDRZEJAK R (2002) Some aspects of arsenic toxicity and carcinogenicity in living organism with special regard to its influence on cardiovascular system, blood and bone marrow. Int J Occup Med Environ Health 15: 101-116.

TAKEDA A (2001) Zinc homeostasis and functions of zinc in the brain Biometals 14: 34-351.

TIAN D, MA H, FENG Z, XIA Y, LE XC, NI Z, ALLEN J, COLLINS B, SCHREINEMACHERS D, MUMFORD JL ( 2001) Analyses of micronuclei in exfoliated epithelial cells from individuals chronically exposed to arsenic via drinking water in inner Mongolia, China. J. Toxicol. Environ. Health A., 64: 473-484.

VAHTER M, BERGLUND M, AKESSON A, LIDEN C (2002) Metals and women's health. Environ Res 88: 145-155.

WANG A, HOLLADAY SD, WOLF DC, AHMED SA, ROBERTSON JL (2006) Reproductive and developmental toxicity of arsenic in rodents: a review. Int J Toxicol 25: 319-331.

YAMANE T (1973) Statistics an introductory analysis. $3^{\text {rd }}$ ed. Harper and Row Publishers, London.

ZHANG C, YAO H, LING B, LIU J (1997) The effect of arsenic on reproduction and offspring development of rats. Wei Sheng Yan Jiu 26: 179-182.

ZHANG C, LING B, LIU J, WANG G (1999) Effect of fluoride-arsenic exposure on the neurobehavioral development of rats offspring. Wei Sheng Yan Jiu., 28: 337-338. 